\title{
Immunomodulatory effects of probiotics and prilled fat supplementation on immune genes expression and lymphocyte proliferation of transition stage Karan Fries cows
}

\author{
Meeti Punetha ${ }^{1}$, A. K. Roy ${ }^{1}$, H. M. Ajithakumar ${ }^{1}$, Irshad Ahmed Para ${ }^{1}$, Deepanshu Gupta ${ }^{1}$, Mahendra Singh ${ }^{1}$ and \\ Jaya Bharati
}

1. Division of Animal Physiology, National Dairy Research Institute, Karnal - 132 001, Haryana, India; 2. Division of Physiology and Climatology, Indian Veterinary Research Institute, Izzatnagar - 243 122, Bareilly, Uttar Pradesh, India. Corresponding author: Mahendra Singh, e-mail: chhokar.ms@gmail.com

Co-authors: MP: meetipunetha283@gmail.com, AKR: royashwani@gmail.com, HMA: ajith.hudedh@gmail.com, IAP: drirshadpara@gmail.com, DG: guptadeepanshu127@gmail.com, JB: jayabvc07@gmail.com

Received: 26-10-2017, Accepted: 16-01-2018, Published online: 18-02-2018

doi: 10.14202/vetworld.2018.209-214 How to cite this article: Punetha M, Roy AK, Ajithakumar HM, Para IA, Gupta D, Singh M, Bharati J (2018) Immunomodulatory effects of probiotics and prilled fat supplementation on immune genes expression and lymphocyte proliferation of transition stage Karan Fries cows, Veterinary World, 11(2): 209-214.

\begin{abstract}
Background and Aim: Probiotics are the living microorganism which when administered improves the digestion and health of the animal. Saccharomyces cerevisiae (SC) improves the humoral and innate immunity of the animal. Prilled fat is a hydrogenated palm oil triglyceride which has been reported to promote the release of cytokines from macrophages. The aim of the study was to evaluate the immunomodulatory effect of probiotic and prilled fat during transition stage in Karan Fries (KF) cows.

Materials and Methods: A total of $12 \mathrm{KF}$ cows at 21 days prepartum were selected and divided into two groups of six animals each. The control group was fed as per the standard feeding practices and the supplemented group cows were supplemented daily with prilled fat at $100 \mathrm{~g} / \mathrm{cow}, \mathrm{SC}$ at $25 \mathrm{~g} / \mathrm{cow}$, and sweetener at $1 \mathrm{~g} / \mathrm{cow}$ in addition to the standard feeding practices from -30 days of prepartum to 21 days of lactation. The sweetener was added to improve the palatability of the feed. The natural sweetener of an African plant leave had 105 times more sweetness than glucose with good aroma. The dry matter intake of the animal was recorded. Plasma samples were collected weekly from all cows for the analysis of blood metabolite beta-hydroxybutyric acid (BHBA). Lymphocytes were isolated from the blood for studying the expression of tumor necrosis factor alpha (TNF- $\alpha$ ) and interleukin-1 $\beta$ (IL-1 $\beta$ ) and for estimating lymphocyte proliferation index (LPI).

Results: The upregulated IL- $1 \beta$ and TNF- $\alpha$ around calving might be possibly associated to the metabolic changes occurring during the transition period and suggest a higher degree of inflammation around parturition. High concentrations of BHBA caused increased expression and synthesis of the pro-inflammatory factors such as TNF- $\alpha$ and IL- $1 \beta$ in supplemented group in primary calf hepatocytes. The LPI was higher in supplemented group as compared to control which suggests a stimulatory effect of unsaturated fatty acids on mitogen-stimulated T-cell proliferation.
\end{abstract}

Conclusion: Dietary supplementation of probiotics, prilled fat, and sweetener alleviated negative energy balance by stimulating feed intake and modulating hepatic lipid metabolism; and both of these additives improved the postpartum health (antioxidant status and immune function) of transition dairy cows.

Keywords: beta-hydroxybutyric acid, crossbred cows, dry matter intake, interleukin-1 $\beta$, lymphocyte proliferation index, prilled fat, Saccharomyces cerevisiae, tumor necrosis factor alpha.

\section{Introduction}

Over the past few decades, production efficiency has increased dramatically due to genetic selection which unfortunately has led to the negative impacts on immunity of animals. Farmers seek natural ways to improve animal health by minimizing the use of antibiotics to achieve higher production. Probiotics in a sense are live, naturally occurring microbes (bacteria and yeast) [1] which when administered in adequate

Copyright: Punetha, et al. Open Access. This article is distributed under the terms of the Creative Commons Attribution 4.0 International License (http://creativecommons.org/licenses/ by/4.0/), which permits unrestricted use, distribution, and reproduction in any medium, provided you give appropriate credit to the original author(s) and the source, provide a link to the Creative Commons license, and indicate if changes were made. The Creative Commons Public Domain Dedication waiver (http:// creativecommons.org/publicdomain/zero/1.0/) applies to the data made available in this article, unless otherwise stated. amounts, confers health benefits on the host. Yeast products and their derivatives (i.e., yeast cell wall products) are utilized for a variety of reasons encompassing performance enhancement and overall benefits to animal health and well-being [2]. The transition period between the late pregnancy and early lactation is under a state of natural immunosuppression, which is due to high concentration of plasma cortisol, decreased dry matter intake (DMI), and decreased production of antioxidant defense near parturition, thus leading to the disruption of normal physiology and contributing to periparturient disorders [3]. In general, dairy cows are under a period of negative energy balance (NEB) during the transition period. Excessive NEB results in fat mobilization which in turn increases blood non-esterified fatty acids (NEFA). Large amounts of NEFA are transported to the liver where they undergo 
$\beta$-oxidation in the hepatocytes to generate more ATP to relieve the NEB. This lipid mobilization is accompanied by alterations in inflammatory responses that modify immune function [4].

Previous researches have shown that the unsaturated fatty acids at physiological concentration inhibit proliferation of mitogen-stimulated lymphocyte [5] which may be due to eicosapentaenoate or arachidonate; however, least inhibition was caused by myristate or palmitate.

Saccharomyces cerevisiae (SC) is used as a substitute of antibiotic feed additive that increases the DMI. $\alpha$-D glucan and $\beta$-D glucan are the major components of the yeast cell wall which interact directly with immune cell and have antioxidant property [6] which affects immune function [7]. SC supplementation not only enhances digestion and nutritive value but has also resulted in better average daily weight gain, feed conversion rates, and blood constituents [8] which in turn has improved both innate and humoral immunity. Organisms which favor the production of lactic acid producing bacteria in the gut, including $\mathrm{SC}$, are well known to stimulate various aspects of the immune system, including phagocytic function of macrophages, natural killer cells, monocytes, and neutrophils [9] which are mainly attributed to yeast cell wall components, mainly $\beta$ glucan and chitin [10]. Dairy calves supplemented with yeast product showed improvement in health and performance [11].

The fatty acid composition of immune and inflammatory cells is sensitive to the changes in fatty acid composition of the diet. The earlier researches have indicated that fatty acid affects the immune response by altering membrane composition and modifying eicosanoids production and cytokine biosynthesis. Animals protect themselves with innate or adaptive mechanism through the production of cytokines and eicosanoids. Dietary fat rich in n-3 and n-6 polyunsaturated fatty acid modulates the inflammatory process. Prilled fat is a hydrogenated palm oil triglyceride consisting of more than $85 \%$ palmitic acid which bypasses rumen and does not affect rumen fermentation [12]. These have been reported to promote the release of cytokine from macrophages [13].

Thus, the aim of the present study was to investigate the combined effect of SC and prilled fat on the DMI, beta-hydroxybutyric acid (BHBA), immune gene expression, and lymphocyte proliferation index (LPI) during transition stage in crossbred Karan Fries (KF) cows.

\section{Materials and Methods}

\section{Ethical approval}

The experimental protocol was duly cleared by the National Dairy Research Institute (NDRI), Animal Ethics Committee.

\section{Experimental site and animals}

The NDRI, Karnal, is situated at an altitude of $250 \mathrm{~m}$ above mean sea level, latitude and longitude position being $29^{\circ} 42^{\prime \prime} \mathrm{N}$ and $79^{\circ} 54^{\prime \prime} \mathrm{E}$, respectively. The maximum ambient temperature in summer goes up to $45^{\circ} \mathrm{C}$ and minimum temperature in winter comes down to $<1{ }^{\circ} \mathrm{C}$ with a diurnal variation in the order of $15-20^{\circ} \mathrm{C}$. For the present study, $12 \mathrm{KF}$ cows at 21 days prepartum were selected from the herd of the NDRI, Karnal.

\section{Experimental design}

The experimental crossbred cows (Holstein Friesian $\times$ Thaparkar) were divided into two groups of six animals each on the basis of most probable production ability. Six cows were kept as control and fed as per the standard feeding practices followed at NDRI farm. The six supplemented group cows were supplemented daily with prilled fat at $100 \mathrm{~g} / \mathrm{cow}, \mathrm{SC}$ at $25 \mathrm{~g} /$ cow, and sweetener at $1 \mathrm{~g} /$ cow in addition to the standard feeding practices from -30 days of prepartum to 21 days of lactation. Plasma samples were collected weekly from all cows for the analysis of blood metabolites (BHBA). Lymphocytes were isolated from the blood for estimating LPI and for studying the expression of TNF $\alpha$ and IL-1 $\beta$. DMI was recorded on -21 , -14 , and -7 (prepartum), 0 (parturition), and on day 7 , 14, 21 (after parturition).

\section{LPI}

The proliferative response of lymphocytes was analyzed using 3-(4,5-dimethylthiazol-2-yl)-2,5-diphenyltetrazolium bromide (MTT) assay [14]. Blood was collected in heparinized vacutainer tubes and centrifuged at $4{ }^{\circ} \mathrm{C}$ in refrigerated centrifuge at $3000 \mathrm{rpm}$ for $30 \mathrm{~min}$ to separate lymphocytes. The buffy coat at the top was harvested and suspended in 1:1 (v/v) Dulbecco's phosphate-buffered saline (DPBS). Total contents were carefully layered on lymphocyte separation medium (Histospaque 1077) at the concentration of $3: 1(\mathrm{v} / \mathrm{v})$ in sterile $15 \mathrm{ml}$ polypropylene centrifuge tube and centrifuged at $2000 \mathrm{rpm}$ for $40 \mathrm{~min}$ at room temperature. The lymphocyte-rich layer present between plasma and lymphocyte separation medium was collected in another sterile $15 \mathrm{ml}$ polypropylene centrifuge tube having $7 \mathrm{ml}$ DPBS and made volume to $10 \mathrm{ml}$ and centrifuged at $1100 \mathrm{rpm}$ for $10 \mathrm{~min}$. The lymphocyte pellet collected at the bottom of polypropylene centrifuge tube was washed twice with DPBS at $1100 \mathrm{rpm}$ for $10 \mathrm{~min}$. After final wash, culture medium was decanted and cells were resuspended in $3 \mathrm{~mL}$ culture medium Roswell Park Memorial Institute medium 1640 with $10 \%$ fetal calf serum and penicillin $\mathrm{G}(100 \mathrm{U} / \mathrm{ml})$, streptomycin sulfate $(100 \mu \mathrm{g} / \mathrm{ml})$, and amphotericin B $(250 \mu \mathrm{g} / \mathrm{ml})$. Trypan blue dye exclusion method was used to determine the viability of lymphocytes, and when the lymphocyte viability was above $95 \%$, the lymphocytes were processed further for culture. The cells were adjusted to $1 \times 10^{6}$ cells per culture well. $200 \mu \mathrm{l}$ of the diluted cell suspension per well in triplicate was placed in 96 well flat-bottomed tissue culture 
plate. The mitogen employed in the present study was phytohemagglutinin (PHA-P) at the concentration of $5 \mu \mathrm{g} / \mathrm{ml}$ of the final culture volume $(200 \mu \mathrm{l})$, a concentration which had been determined previously to provide maximal stimulation of bovine lymphocytes. 20 $\mu 1$ PHA-P was added to the wells. In all the cases, final culture volume was $200 \mu \mathrm{l}$. The cells were allowed to proliferate with and without mitogen (PHA-P). The blank wells consisted of $200 \mu 1$ of culture media only. The culture plates were incubated at $37^{\circ} \mathrm{C}$ in a humidified $\mathrm{CO}_{2}$ incubator $\left(95 \%\right.$ air and $5 \% \mathrm{CO}_{2}$ ) for $36 \mathrm{~h}$. The proliferative response of lymphocyte was estimated using the colorimetric MTT (tetrazolium). $20 \mu \mathrm{L}$ of the MTT solution $(5 \mathrm{mg} / \mathrm{mL}$ dissolved in DPBS and filtered through $0.22 \mu \mathrm{m}$ Millex-GV filter unit) was added to each well. The plates were again incubated for $4 \mathrm{~h}$ at $37^{\circ} \mathrm{C}$ in humidified $\mathrm{CO}_{2}$ incubator. Thereafter, the supernatant was pipetted out completely without disturbing formazan crystal layer, and $150 \mu \mathrm{L}$ of dimethyl sulfoxide was added to each well. After incubating the plate at room temperature for $15 \mathrm{~min}$, it was shaken on a microplate shaker and the optical density was read using ELISA reader (Microscan MS-5608A) in dual wavelength measuring system, at a wavelength of $570 \mathrm{~nm}$ and a reference wavelength of $630 \mathrm{~nm}$. Lymphocyte blastogenic response was expressed as proliferation index (PI) and was calculated as follows:

Proliferation index (PI) $=$ OD of the mitogen-stimulated cells/OD of the non-stimulated cells.

\section{Primers}

Primers were designed using FAST PCR (version 6.2.73) software details as given in Table-1.

\section{Gene expression of TNF- $a$ and IL-1 $\beta$}

Total RNA was isolated from 8 to $10 \mathrm{ml}$ of peripheral blood using the RNeasy Midi Kit (Qiagen), and the concentration and purity of the RNA samples were determined using a NanoDrop. All RNA samples had an $\mathrm{A}_{260 / 280}$ absorbance ratio of between 1.85 and 2.0. RNA undergoes the process of reverse transcription by First Strand cDNA Synthesis Kit (Thermo Science) as the manufacturer recommends. Quantitative real-time polymerase chain reaction (PCR) was performed using SYBR Green, an asymmetrical cyanine dye in PCR Master Mix (Amplicon), primer pairs (Table-1), and an ABI stepOne $^{\mathrm{TM}}$ (Applied Biosystems) real-time PCR machine.

\section{Statistical analysis}

The result presented as mean \pm standard error of the mean and was analyzed using SPSS (Statistical Package for the Social Sciences) 13.0 software (SPSS Incorporated, Chicago, IL, USA) by two-way analysis of variance followed by Duncan's multiple range test. $\mathrm{p}<0.05$ is considered statistically significant.

\section{Results}

The mean DMI ranged from $10.96 \pm 0.29$ to $11.4 \pm 0.17 \mathrm{~kg} / \mathrm{d}$ in control and $11.88 \pm 0.28$ to $13.8 \pm 0.29 \mathrm{~kg} / \mathrm{d}$ in supplemented groups (Figure-1). The DMI varied significantly $(p<0.01)$ between groups and period. A decreasing trend was observed in both the groups during prepartum period from 21 day to calving, and after that, DMI increased linearly. The plasma BHBA concentration varied significantly between the groups. Plasma BHBA concentration ranged between $0.43 \pm 0.01$ and $0.59 \pm 0.01$ $\mathrm{mM} / \mathrm{L}$ in control and $0.39 \pm 0.008$ to $0.50 \pm 0.01 \mathrm{mM} / \mathrm{L}$ in supplemented group during the experimental period (Figure-2). The expression of IL-1 $\beta$ and TNF- $\alpha$ was upregulated during transition period regardless of the diet (Figures-3 and 4). However, supplemented group showed significantly $(\mathrm{p}<0.01)$ higher expression than the control group. The LPI was higher in the supplemented group as compared to control with minimum values on 7 day prepartum in both the groups (Figure-5). However, results did not vary significantly between the groups. The average value of LPI varied from $1.20 \pm 0.05$ to $1.29 \pm-0.03$ in control group and $1.24 \pm 0.03$ to $1.43 \pm 0.04$ in supplemented group (Figure-5).

\section{Discussion}

The metabolic characteristics of cows during the transition are markedly different from those of other periods. Cows experience serious imbalance in the energy level, amino acids, and other nutrients due to DMI reduction and hormone-induced adaptations [15]. A deficiency in energy intake results in adipose fat mobilization and enhanced activity of lipid metabolic cycles in the liver of dairy cows. Therefore, improving energy status of cow during the transition period is a top priority in dairy nutrition. The DMI of supplemented group was significantly $(\mathrm{p}<0.01)$ improved in the following experiment. Yeast was found to improve

Table-1: Target genes, primer sequence $\left(5^{\prime}-3^{\prime}\right)$, amplicon length, annealing temperature, and EMBL accession number.

\begin{tabular}{|c|c|c|c|c|}
\hline Gene & Primer sequence & Size & $\operatorname{Tm}\left({ }^{\circ} \mathrm{C}\right)$ & Accession No \\
\hline \multicolumn{5}{|l|}{ IL-1 $\beta$} \\
\hline $\begin{array}{l}\text { Sense } \\
\text { Antisense }\end{array}$ & $\begin{array}{l}\text { GAGGAGCATCCTTTCATTCATC } \\
\text { TTCCTCTCCTTGTACGAAGCTC }\end{array}$ & 229 & 56 & $\times 54796$ \\
\hline \multicolumn{5}{|l|}{ TNF-a } \\
\hline $\begin{array}{l}\text { Sense } \\
\text { Antisense }\end{array}$ & $\begin{array}{l}\text { ACTCAGGTCCTCTTCTCAAGCC } \\
\text { ATGATCCCAAAGTAGACCTGCC }\end{array}$ & 774 & 56 & NM_173966 \\
\hline \multicolumn{5}{|l|}{ GAPDH } \\
\hline $\begin{array}{l}\text { Sense } \\
\text { Antisense }\end{array}$ & $\begin{array}{l}\text { AGCTCATTTCCTGGTACGACAA } \\
\text { AGGGTCCAGGGACCTTACTC }\end{array}$ & 184 & 59 & \\
\hline
\end{tabular}

IL-1 $\beta=$ Interleukin-1 $\beta$, TNF- $a=$ Tumor necrosis factor alpha 


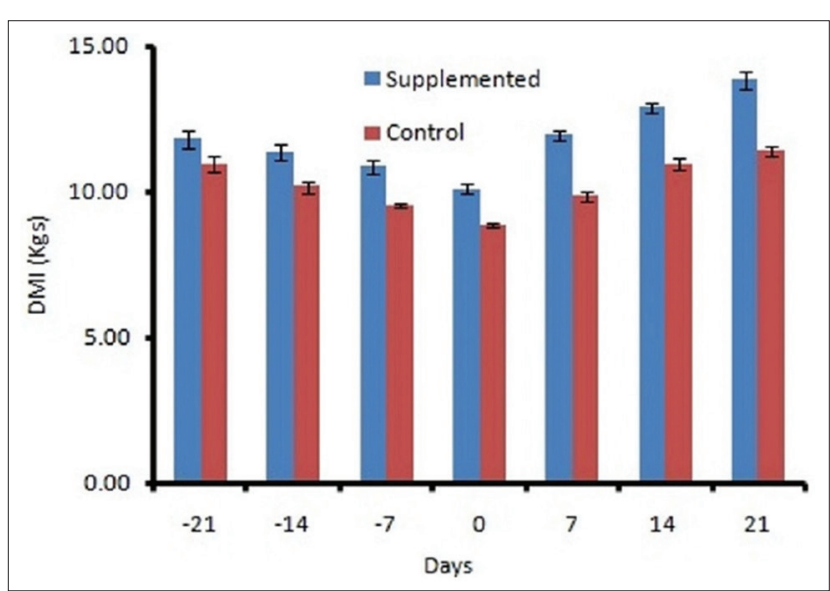

Figure-1: Effect of prilled fat and Saccharomyces cerevisiae on Dry Matter Intake in crossbred cows.

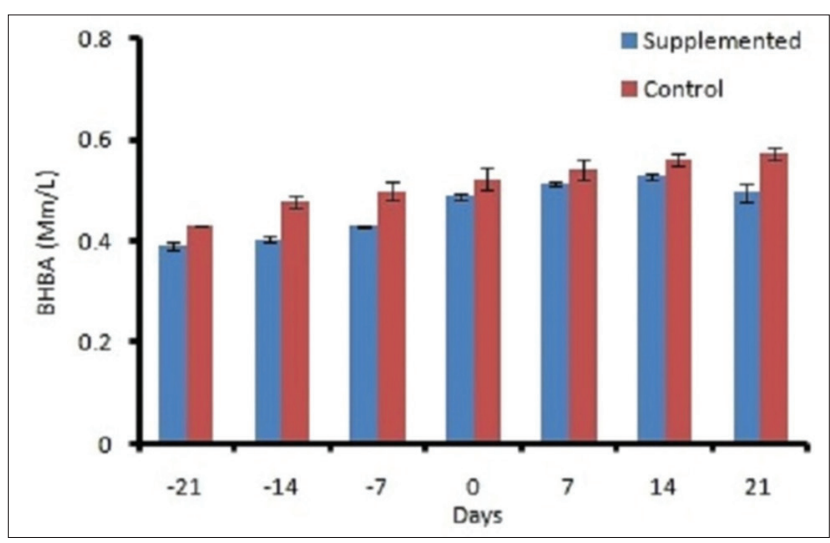

Figure-2: Effect of prilled fat and Saccharomyces cerevisiae on Beta Hydroxy butyric acid level in crossbredcows.

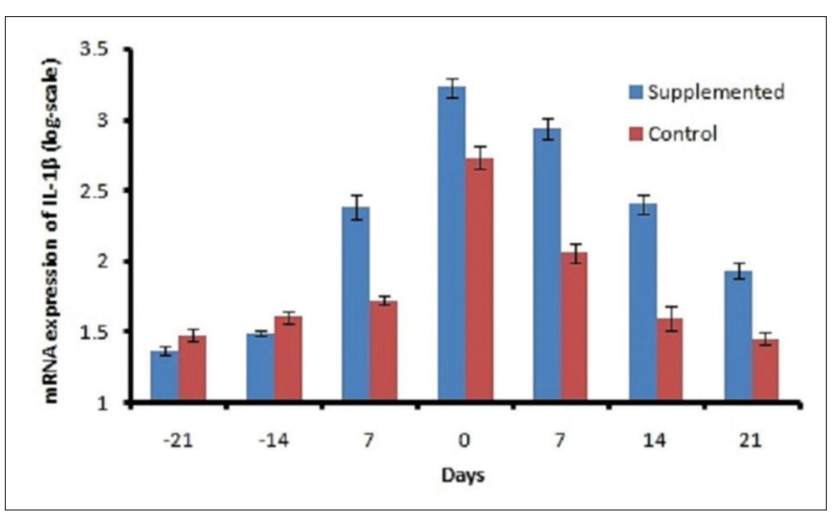

Figure-3: Effect of prilled fat and Saccharomyces cerevisiae on mRNA expression of IL-1 beta in crossbred cows.

the feed intake [16,17]. Since prilled fat does not affect DMI [18], the increased DMI in this study was attributed to yeast supplementation as later improve the feed intake $[19,20]$. Roberts et al. [21] conducted an experiment in which animals were fed high energy ration during early lactation and showed lower plasma BHBA concentrations as compared to that of cows on a low energy ration which are in agreement with our study. Yeast supplementation led to the improved energy balance and reduced NEFA level of animals [22]. SC increased the total number of ruminal

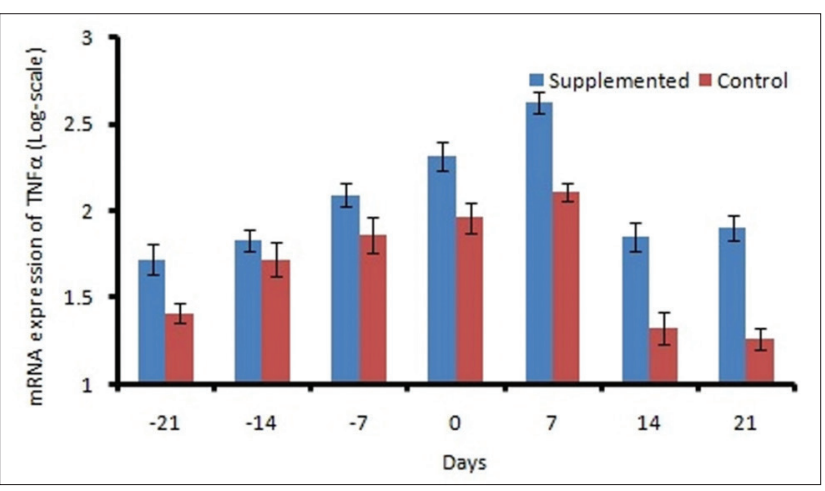

Figure-4: Effect of prilled fat and Saccharomyces cerevisiae on mRNA expression of TNFa in cross bred cows.

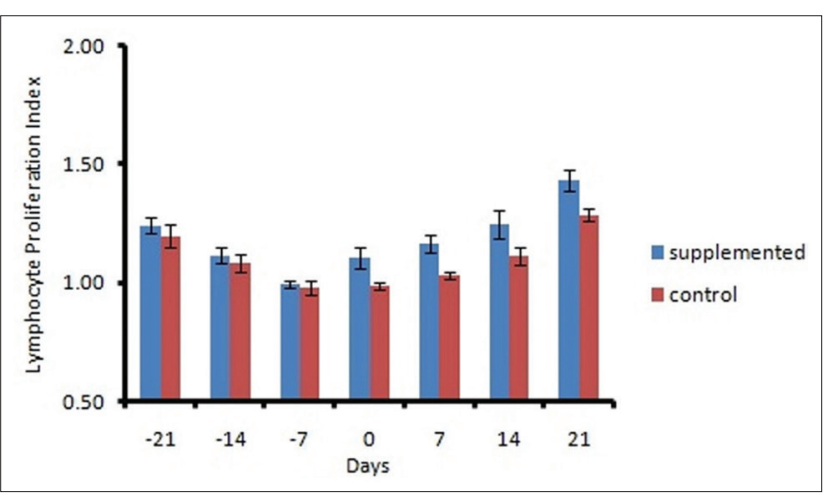

Figure-5: Effect of prilled fat and Saccharomyces cerevisiae on Lymphocyte proliferation Index of crossbred cows.

bacteria and cellulolytic bacteria and the proportion of propionate but decreased lactate concentration and thus increased the DMI of the animal [23]. BHBA concentration declines during the dry period with the increasing DMI [24].

Elevated levels of NEFA and ketone bodies in transition cows are the principal stimulators of immune-suppression, inflammatory responses, and metabolic disorders. IL-1 $\beta$ showed a significant difference between the group and weeks $(p<0.01)$. Production of cytokines such as IL- $1 \beta$ and TNF- $\alpha$ increased in response to pro-inflammatory stimuli [25]. In the current experiment, the upregulated IL- $1 \beta$ and TNF- $\alpha$ around calving could be correlated to the metabolic changes occurring during the transition which suggests a higher degree of inflammation around parturition. Immune mediators including IL-1 $\beta$ and TNF- $\alpha$ play an important role in pathogen clearance [26]. These cytokines stimulate the production of antimicrobial peptides to eradicate the pathogenic bacteria. The higher expression $(\mathrm{p}<0.01)$ of IL-1 $\beta$ and TNF- $\alpha$ in supplemented group might be due to increased DMI which resulted in higher glucose availability for cells to respond. BHBA was statistically significant $(p<0.01)$ between the groups. BHBA activates $\mathrm{NF}-\kappa \mathrm{B}$-induced hepatocyte injury by regulating the expression of TNF- $\alpha$ and IL-1 $\beta$ in hepatocytes [27]. Cytokines were found to be upregulated significantly in broilers supplemented with SC [28]. 
Investigations showed that PHA-P stimulated lymphocyte proliferation response on the day of calving was significantly low in all cows. The cell-mediated immune responses were not influenced by the supplement mixture. The supplementation of prilled fat, SC, and sweetener had no significant effect on the stimulation index of mitogen-induced lymphocyte blastogenesis between control and the supplemented groups. However, the increased value of stimulation index on day 21 of treated group shows that the animals might have recovered from parturition stress. The events involved in lymphocyte activation and proliferation, including signal transduction and receptor expression, are membrane-associated. It is well known that the membrane functions are influenced by the fatty acid composition of the membrane phospholipids, probably because of changes in membrane fluidity. Lymphocytes from different tissues respond differently to dietary lipid manipulation, due to the difference in the ability of different cells to take up and metabolize the fatty acids. The experiment suggests that supplementation stimulated lymphocyte proliferation through the production of IL-1 $\beta$ and TNF- $\alpha$ by stimulated lymphocytes. The yeast extract used in the study contains two bioactive components: Glucan and mannan-oligosaccharides. It was reported that glucan increased total leukocyte number in broiler chicks [29]. However, the LPI in the supplemented group was not significant. Since the effects of fatty acids on lymphocyte proliferation are concentration and time-dependent [5], the variable immunomodulator effects of the yeast extracts may be due to structural differences in glucan [30].

\section{Conclusion}

Dietary supplementation of probiotics, prilled fat, and sweetener alleviated NEB by stimulating feed intake and modulating hepatic lipid metabolism, and both of these additives improved the postpartum health (antioxidant status and immune function) of transition dairy cows. The DMI was improved in the supplemented group when compared with control group. BHBA concentration was lower in the supplemented group which shows improved energy status of animal. The lymphocyte proliferation was higher in supplemented group than the control which has led to higher expression of IL-1 $\beta$ and TNF $\alpha$. In conclusion, the results showed that the probiotics and prilled fat together improved the immune status of the animals.

\section{Authors' Contributions}

MP carried out the experiment, analyzed the data and drafted the manuscript. AKR and MS designed the experiment and also supervised the laboratory work. $\mathrm{AKH}, \mathrm{IP}$, and DG helped in conducting research and contributed to statistical analysis. MP and JB helped to draft the manuscript. JB, MP, and IP reviewed the manuscript efficiently. All authors read and approved the final manuscript.

\section{Acknowledgments}

The authors thank Director, ICAR-National Dairy Research Institute, Karnal, for providing necessary facilities for the above research work. The grant used under BRNS project no. 2013/35/48-RTAC, Mumbai, is thankfully acknowledged.

\section{Competing Interests}

The authors declare that they have no competing interests.

\section{References}

1. Kenney, N. (2013) Impact of Direct-fed Microbials on Nutrient Utilization in Beef Cattle. MSc thesis, University of Kentucky,UKnowledge, UK.

2. Wang, D., Zhou, L., Zhou, H., Hou, G. and Shi, L. (2017) Effects of dietary $\alpha$-lipoic acid on carcass characteristics, antioxidant capability and meat quality in Hainan black goats. Ital. J. Anim. Sci., 16(1): 61-67.

3. Gitto, E., Reiter, R.J., Karbownik, M., Tan, D.X., Gitto, P., Barberi, S. and Barberi, I. (2002) Causes of oxidative stress in the pre-and perinatal period. Biol. Neonate, 81(3): 146-157.

4. Mateus, L., Costa, L., Bernardo, F. and Robalo, S.J. (2002) Influence of puerperal uterine infection on uterine involution and postpartum ovarian activity in dairy cows. Reprod. Domest. Anim., 37(1): 31-5.

5. Calder, P.C., Bond, J.A., Bevan, S.J., Hunt, S.V. and Newsholme, E.A. (1991) Effects of fatty acid on proliferation on concanavalin - A stimulated rat lymph node lymphocytes. Int. J. Biochem., 23(5-6): 579-588.

6. Kogan, G., Stasko, A., Bauerova, K., Polovka, M., Soltes, L., Brezova, V., Navarova, J. and Mihalova, D. (2005) Antioxidant properties of yeast $(1 \rightarrow 3)-\beta$-D-glucan studied by electron paramagnetic resonance spectroscopy and its activity in the adjuvant arthritis. Carbohydr. Polym, 61(1): 18-28

7. Gao, J., Zhang, H.J., Yu, S.H., Wu, S.G., Yoon, I., Quigley, J., Gao, Y.P. and Qi, G.H. (2008) Effects of yeast culture in broiler diets on performance and immunomodulatory functions. Poultry Sci, 87(7): 1377-1384.

8. Mousa, K.M., El-Malky, O.M., Komonna, O.F. and Rashwan, S.E. (2012) Effect of some yeast and minerals on the productive and reproductive performance in ruminants. J. Am. Sci., 8(2): 291-303.

9. Patterson, R., Nerren, J., Kogut, M., Court, P., VillarrealRamos, B., Seyfert, H.M., Dalby, P. and Werling, D. (2011) Yeast-surface expressed BVDV E2 protein induces a Th1/ Th2 response in naïve T cells. Dev. Comp. Immunol., 1(1): 107-111.

10. Tewary, A. and Patra, B.C. (2011) Oral administration of baker's yeast (Saccharomyces cerevisiae) acts as a growth promoter and immunomodulator in Labeo rohita (Ham.). J Aquac. Res. Dev., 2(1): 1-7.

11. Laxmi, N.A., Sehgal, J.P. and Kumar, B.S.B. (2016) Supplementation of fermented yeast culture augments the growth and reduces the age at puberty in male Murrah buffalo calves. Buffalo Bull., 35(2): 179-189.

12. Mahendra, S., Sehgal, J.P., Roy, A.K., Pandita, S. and Rajesh, G. (2014) Effect of prill fat supplementation on hormones, milk production and energy metabolites during mid-lactation in crossbred cows. Vet. World, 7(6): 384-388.

13. Majtan, J., Kogan, G., Kovacova, E., Bilikova, K. and Simuth, J. (2005) Stimulation of TNF-alpha release by fungal cell wall polysaccharides. Z. Naturforschung $C$, 60(11-12): 921-926.

14. Riss, T.L., Moravec, R.A., Niles, A.L., Duellman, S., Benink, H.A., Worzella, T.J., Minor, L. (2016) Cell Viability Assays. Source Assay Guidance Manual. Eli Lilly 
\& Company, Bethesda (MD).

15. Roche, J.R., Bell, A.W., Overton, T.R. and Loor, J.J. (2013) Nutritional management of the transition cow in the $21^{\text {st }}$ century?-A paradigm shift in thinking. Anim. Prod. Sci., 53(9): 1000-1023.

16. Alugongo, G.M., Xiao, J., Wu, Z., Li, S., Wang, Y. and Cao, Z. (2017) Utilization of yeast of Saccharomyces cerevisiae origin in artificially raised calves. J. Anim. Sci. Biotechnol., 8(1): 34 .

17. Mostafa, T.H., Elsayed, F.A., Ahmed, M.A. and Elkholany, M.A. (2014) Effect of using some feed additives (tw-probiotics) in dairy cow rations on production and reproductive performance. Egyptian J. Anim. Prod., 51(1): 1-11.

18. Sharma, S., Singh, M., Roy, A.K. and Thakur, S. (2016) Effect of pre-partum prilled fat supplementation on feed intake, energy balance and milk production in Murrah buffaloes. Vet. World, 9(3): 256.

19. Kawas, J.R., Garcia-Castillo, R., Fimbres-Durazo, H., Garza-Cazares, F., Hernandez-Vidal, J.F.G., OlivaresSaenz, E. and Lu, C.D. (2007) Effects of sodium bicarbonate and yeast on nutrient intake, digestibility, and ruminal fermentation of light-weight lambs fed finishing diets. Small Rum. Res., 67(2): 149-156.

20. Chaucheyras-Durand, F., Walker, N.D. and Bach, A. (2008) Effects of active dry yeasts on the rumen microbial ecosystem: Past, present and future. Anim. Feed Sci. Tech., 145(1): $5-26$.

21. Roberts, T., Chapinal, N., LeBlanc, S.J., Kelton, D.F., Dubuc, J. and Duffield, T.F. (2012) Metabolic parameters in transition cows as indicators for early-lactation culling risk. J. Dairy Sci., 95(6): 3057-3063.

22. Al Ibrahim, R.M., Whelan, S.J., Pierce, K.M., Campion, D.P., Gath, V.P. and Mulligan, F.J. (2013) Effect of timing of post-partum introduction to pasture and supplementation with Saccharomyces cerevisiae on milk production, metabolic status, energy balance and some reproductive parameters in early lactation dairy cows. J. Anim. Physiol. Anim. Nutr., 97(s1): 105-114.

23. Al Ibrahim, R.M., Gath, V.P., Campion, D.P., McCarney, C., Duffy, P. and Mulligan, F.J. (2012) The effect of abrupt or gradual introduction to pasture after calving and supplementation with Saccharomyces cerevisiae (Strain 1026) on ruminal $\mathrm{pH}$ and fermentation in early lactation dairy cows. Anim. Feed Sci. Tech., 178(1): 40-47.

24. Roche, J.R., Kolver, E.S. and Kay, J.K. (2005) Influence of precalving feed allowance on periparturient metabolic and hormonal responses and milk production in grazing dairy cows. J. Dairy Sci., 88(2): 677-689.

25. Ramadori, G. and Armbrust, T. (2001) Cytokines in the liver. Eur. J. Gastroenterol. Hepatol., 13(7): 777-784.

26. Janeway, C.A. Jr., Travers, P., Walport, M. and Shlomchik, M.J. (2001) Infectious agents and how they cause disease; Immunobiology: The Immune System in Health and Disease. Garland Publishing, New York. p382-388.

27. Shi, X., Li, X., Li, D., Li, Y., Song, Y., Deng, Q., Wang, J., Zhang, Y., Ding, H., Yin, L., Zhang, Y., Wang, Z., Li, X. and Liu, G. (2014) Signaling pathway to promote the expression of pro-inflammatory factors in calf hepatocytes. Cell Physiol. Biochem., 33(4): 920-932.

28. Chou, W.K., Park, J., Carey, J.B., McIntyre, D.R. and Berghman, L.R. (2017) Immunomodulatory effects of Saccharomyces cerevisiae fermentation product supplementation on immune gene expression and lymphocyte distribution in immune organs in broilers. Front. Vet. Sci., 4(4): 37.

29. Fleischer, L.G., Gerber, G., Liezenga, R.W., Lippert, E., Scholl, M.A. and Westphal, G. (2000) Blood cells and plasma proteins of chickens fed a diet supplemented with 1,3/1,6-beta-D-glucan and enrofloxacin. Archiv Fur Tiernahrung, 53(1): 59-73.

30. Brown, G.D. and Gordon, S. (2003) Fungal beta-glucans and mammalian immunity. Immunity, 19(3): 311-315.

$* * * * * * * *$ 